Preservation of historic apparatus

Some time ago a Joint Working Party between the Royal College of Pathologists and the Institute of Medical Laboratory Science was set up in an endeavour to collect and preserve the old, obsolete, and now historic apparatus that was once used in medical laboratories. Many of the instruments that were employed have been supplanted by more modern and more sophisticated equipment. There is, we believe, a growing urgency to preserve examples of laboratory apparatus that are no longer used.

The Working Party's quest has not been unsuccessful, and we now hold about 400 items of obsolete instruments, which are, and will increasingly be, of great historic interest. A few people from relatively few laboratories have made most of the collection but we believe that there is still a great store of untapped old equipment, although rapidly diminishing, in many laboratories and possibly in the hands of some of the older general practitioners, who did their own tests, scattered throughout the country.

We would therefore appeal to those who may have such equipment to search it out and let us know about it. It may be that some would wish to retain it; if so we would like a copy of the list of equipment held. Some, no doubt, would like to get rid of it on permanent loan, and we will do our best to store it. A little extra effort on the part of laboratory workers could vastly increase the interest and variety of the collection. Please help us if you possibly can in this matter. It may take a little time on your part, but it could increase your effective storage space. It will undoubtedly be of the greatest value to future generations of laboratory workers to see the tools of the trade on which their present work was based.

Offers of equipment (NOT equipment itself) should be sent in the first instance to Dr J. B. Penfold, Pathology Laboratory, St. Mary's Hospital, Colchester or to $\mathrm{Mr}$ A. G. W. Webb, Bardis, 50 Walton Road, Frinton-on-Sea, Essex. It is hoped that eventually the collection will be housed in the Science Museum in London or some similar institution.
A. D. FARR
W. D. FOSTER
G. K. MCGOWAN
G. C. PASCOE
Members of the
J. B. PENFOLD Joint Working
W. H. VALENTINE
A. G. W. WEBB

\section{Thymidine mutants}

May we comment on the interesting paper by Stokes and Lacey (1978).

They kindly refer to our work, but we think it is important to emphasise that the phenomenon we described is rare, certainly at present, and the knowledge that it can occur does not detract from the usefulness of cotrimoxazole in the great majority of patients.

We feel that our method of sensitivity testing using thymidine-free media (ISA Oxoid, SAF Mast) is an adequate guide to treatment. Failure of an organism to grow on these media alerts us to the phenomenon described in our paper (Maskell et al., 1978). Possibly the method of sensitivity testing suggested by Stokes and Lacey may be useful, but it needs confirmation in the context of the treatment of patients.

ROSALIND MASKELL and O. A. OKUBADEJO Public Health Laboratory, St. Mary's General Hospital, East Wing, Milton Road, Portsmouth PO3 6AQ

\section{References}

Maskell, R., Okubadejo, O. A., Payne, R. H., and Pead, L. (1978). Human infections with thymine-requiring bacteria. Journal of Medical Microbiology, 11, 33-45.

Stokes, A., and Lacey, R. W. (1978). Effect of thymidine on activity of trimethoprim and sulphamethoxazole. Journal of Clinical Pathology, 31, 165-171.

The authors comment as follows:

We do not accept the interpretation of Drs Maskell and Okubadejo that, because thymidine (or thymine) mutants are isolated infrequently, cotrimoxazole therapy is rarely affected.

Such mutation occurs at very low frequency in vitro, and large amounts of thymidine could well occur in vivo, without the isolation of these mutants.

R. W. LACEY and ANNE STOKES, West Norfolk and King's Lynn General Hospital, London Road, King's Lynn, Norfolk, PE34 5QD

\section{Book review}

Lymphoreticular Disease: an Introducti $\overrightarrow{\overline{\omega_{3}}}$ for the Pathologist and Oncologist. $B y \frac{T^{*}}{0}$. Carr, B. W. Hancock, L. Henry, and Milford Ward. (Pp. xi + 214; illustratef; £9-25.) Oxford: Blackwell Scientific Puђ lications. 1977.

Pathology monographs covering the various systems of the body have beer coming out in a steady stream over the past quarter century. A notable deficien until recently has been the lack of से English language monograph on the lymphoreticular system, and this bodk from a group of Sheffield workers is therio fore to be welcomed. The editor, in higs preface, makes it clear that the book os intended for the histopathologist, the physician and the oncologist in training음 as an introduction'. Although there is $-\mathrm{a}$ chapter at the end on investigation and treatment of lymphomas, the greater part of the book is concerned with histङpathology, and the text is necessarity accompanied by numerous photomicres graphs. Some of these are good, but t@o many appear to show 'just a lot of smat round cells' and are not particulary helpful in distinguishing one condition from another in this difficult area $\overline{\mathrm{Qf}_{\mathrm{f}}}$ histopathology. Nor do the descriptio s in the text always bring out the salient points which differentiate, for example, follicular hyperplasia from folliculagr lymphoma. The inclusion of a number $\mathrm{gf}^{\mathrm{f}}$ high quality electron micrographs cleary reflects the interest of the senior author. Many are useful, but it may be argued that nine electron micrographs of Hodgkioss disease are excessive in a book of this size. One may also question the value of sorioe of the large clinical photographs. TRe coverage is wide-perhaps too wide, for the descriptions of some conditions a too brief to be useful, but leukaemias general have been somewhat arbitrary excluded.

Regretfully this monograph cannot $\stackrel{\mathrm{Fe}}{\mathrm{ge}}$ recommended as an essential bench boak for the aspiring histopathologist, althou as an introduction to the subject it cofp tains much of value.

A. G. STANSFEQ 